Analyses by race seek to reflect racial inequalities in access to health services. To describe avoidable IM from the Brazilian List of Avoidable Deaths (LBE). A descriptive study of avoidable child deaths among Caucasians and Afro-descendents in Belo Horizonte from 2000 to 2007. We calculated the infant mortality rate (IMR), the neonatal IMR (N IMR) and Postneonatal IMR (PN IMR), infant mortality proportional to avoidable cause (IMPAC) and infant mortality proportional to ill-defined causes (IDC). There was a reduction of $31.23 \%$ in the IMR, of $32.6 \%$ in the N IMR and of $28.4 \%$ in the PN IMR. Avoidable deaths accounted for $70.2 \%$ of the total, and this percentage was higher (73.8\%) among Afrodescendants. The highest percentage occurred in the subgroup "newborn care" (48.6\%). Afro-descendants accounted for $52.9 \%$ and Caucasians for $42.8 \%$ of these deaths. The main causes were respiratory and cardiovascular diseases, with the highest proportion for Afro-descendants (29.8\%). Deaths from IDC decreased 23.8\% in the period, but the largest proportion occurred among Afrodescendants $(4.5 \%)$. Filling in of information on the variable race/colour still presents problems. We observed a high number of deaths by "newborn care" and "pregnancy care." We detected racial inequality in IMPAC, Afro-descendant children having the highest percentages. These inequalities are influenced by socio-economic status and access to health services. The health services play a fundamental role in reducing the gaps in infant mortality observed in this study.

\section{P1-138 FRAILTY SYNDROME IN BRAZILIAN OLDER ADULTS}

doi:10.1136/jech.2011.142976d.31

Y Duarte, ${ }^{*}$ M L Lebrão, L P Corona, D P Nunes, J L Santos, T S Alexandre. University of Sao Paulo, Sao Paulo, Brazil

Introduction The increase in the percentage of older adults is increasing more rapidly today in the developing world than previously occurred in the developed nations. These trends have important implications for understanding the mechanisms of population ageing and for all aspects of contemporary life. Frailty is considered to be a wasting syndrome that elevates the risk for a variety of adverse outcomes.

Objectives Using Fried's model, identify frailty syndrome and associated factors in Brazilian older adults.

Methods Data comes from a longitudinal survey-SABE (Health, Well-being and Ageing), with a multistage clustered sample of 1413 people aged $\geq 65$ years-old in Sao Paulo-Brazil in 2006 . Frailty was defined as the presence of 3 or + of five criteria of the Fried's model, unintentional weight loss, exhaustion, weakness, slowness and low physical activity. Pre-frail was defined as the presence of one/two items. Multivariable linear regressions identified associated factors with frailty at baseline.

Results Prevalence of pre-frail was $45.9 \%$ and frailty was $12.9 \%$. Associated factors adjusted by age and gender included less education $(\mathrm{OR}=2.40, \mathrm{p}=0.03)$; fair/poor self-reported health $(\mathrm{OR}=2.81$ / $3.63, \mathrm{p}=0.01)$, stroke $(\mathrm{OR}=6.54, \mathrm{p}=0.02)$, depressive symptoms $(\mathrm{OR}=4.55, \mathrm{p}<0.00)$, disability $\geq 1 \mathrm{ADL}(\mathrm{OR}=2.79, \mathrm{p}=0.02)$ and $\geq 1 \mathrm{IADL}(\mathrm{OR}=3.81, \quad \mathrm{p}=0.04)$, hospitalisation last 12 months $(\mathrm{OR}=3.81, \mathrm{p}=0.01)$. There was poor concordance between frailty and disability (3.4\%) and modest with comorbidities (26.2\%). These three conditions were present in $55.1 \%$ and frailty alone was identify in $15.2 \%$ of older.

Conclusion Recognition of associated factors with frailty syndrome may help to perform active prevention and intervention actions and, consequently, maximise older quality of life.
P1-139 FRAILTY IMPACT ON OLDER BRAZILIAN SURVIVAL: 3 YEARS FOLLOW-UP SURVEY

doi:10.1136/jech.2011.142976d.32

Y Duarte, ${ }^{*}$ L P Corona, M L Lebrão, J L F Santos. University of Sao Paulo, Sao Paulo, Brazil

Objective In this study we will analyse the survival curve of older Brazilians ( $\geq 75$ years) according frailty categories (not frail, intermediate, frail) in a large, well-defined sample of older Brazilian in 3 years follow-up.

Methods Data comes from a longitudinal survey-SABE Study (Health, Well-being and Ageing) that began in 2000 with a sample $(\mathrm{n}=2143$ ) older adults ( $\geq 60$ years) living in São Paulo/Brazil.In 2006 1115 older adults were re-interviewed when the frailty analysis (Fried's model) began. The follow-up were analysed with data from four waves, on 2008 and 2009. Survival analysis was done based on data of 2006 ( $n=687$ olders $\geq 75$ years) up to 2009 (death analyses). Kaplan-Meier Survival Analysis was used to analyse the results considering frailty categories in baseline. Cox proportional hazards model was tested using social demographic and health conditions.

Results There were 134 deaths and 116 follow-up losses. In survival analysis, the three strata (not frail, intermediate and frail) did not reach the median survival; only frail elders reached $25 \%$ survival time, with 17.2 months, so frail elders presented the worst prognosis. The HR for intermediate is 1.94 and 5.47 for frail, in relation to robust ( $p$ trend $=0.000$ ). The hazard adjusted model showed a HR 1.6 for pre-frail and 2.9 for frail $(p<0.01$; $p$ trend $=0.003)$.

Conclusions Frailty is associated with mortality in Brazilian elders. Recognition of variables involved in frailty may help to perform active prevention and intervention actions and, consequently, maximise survival.

\section{P1-140 WHAT KINDS OF HAND INJURIES ARE MORE LIKELY TO RESULT IN AMPUTATION? AN ANALYSIS OF 6549 HAND INJURIES}

doi:10.1136/jech.2011.142976d.33

${ }^{1} \mathrm{R}$ Durusoy, ${ }^{* 1} \mathrm{~A}$ Davas, ${ }^{2} \mathrm{M}$ Kayalar, ${ }^{2} \mathrm{E}$ Bal, ${ }^{1} \mathrm{~F}$ Aksu, ${ }^{2} \mathrm{~S}$ Ada. ${ }^{1}$ Department of Public Health, Ege University Medical School, Izmir, Turkey; ${ }^{2}$ EMOT Hospital, Izmir, Turkey

Aim The aim of this study was to identify risk factors for hand amputations using the records of a hospital in Turkey specialising in hand and microsurgery.

Method This is a restrospective analytical chart study. We analysed 6549 hand injuries treated between 1992 and 2005. Researchers coded the variables "intent", "activity when injured", "mechanism of injury", "object/substance producing injury" and "place of occurrence" according to the International Classification of External Causes of Injuries (ICECI), 2004. $\chi^{2}$ Test and univariate logistic regression analyses were used to explore the effects of ICECI categories and gender, age, social security, residence, season on the presence of an amputation.

Results There were 2899 (44\%) hand amputations and 2812 (97\%) were finger amputations. Left-side injuries were more prone to amputation $(\mathrm{OR}=1.13$, CI 1.03 to 1.25$)$. The risk of amputation was higher in men, workers and those in the 15-24 and 45-54 year-old age groups. Compared to home, commercial area was the place with highest risk $(\mathrm{OR}=4.06$, $\mathrm{CI} 2.52$ to 6.54$)$, followed by farm $(\mathrm{OR}=3.64$, CI 2.66 to 4.98$)$ and industrial/construction area $(\mathrm{OR}=3.12$, CI 2.55 to 3.82$)$. The majority of amputations occurred in industrial/construction areas (87\%). Among objects/substances producing injury, watercraft ( $\mathrm{OR}=49.5$, CI 6.2 to 394.9) led to the highest risk of amputation and contact with machinery $(\mathrm{OR}=9.04$, CI 7.53 to 10.85 ) was the mechanism with highest risk. Press machines were the most frequent objects causing amputation both 